\title{
A Study on Effects of Education Program for Cognitive Rehabilitation
}

\author{
Young-Sun Park ${ }^{1}$ and Young-Ju Jee ${ }^{2}$ \\ ${ }^{1}$ Dept. of Nursing, Kyungbok University, 154 Sinpyeong-ro Sinbuk-myeon, Pocheon- \\ si, Gyeonggi-do 11138, Korea \\ ${ }^{2}$ Dept. of Nursing, Kyungnam University, Woryeongbuk 16-gil Masanhappo-gu, \\ Changwon-si, Gyeongsangnam-do 631-701, Korea \\ 'yspark@kyungbok.ac.kr, ${ }^{2}$ jeeyoungju@kyungnam.ac.kr
}

\begin{abstract}
This study was a one-group pretest-posttest study to examine the effects of cognitive rehabilitation program education on dementia attitudes and geriatric nursing self-efficacy. The results showed that the dementia attitude knowledge, dementia attitude stability, and total score of dementia attitude were not statistically significant. However, the average score showed a slight improvement. And there was no statistically significant difference in geriatric nursing self-efficacy, but it showed a slight improvement in the average score. Based on the results of the research, the cognitive rehabilitation program education is an effective and beneficial program for the care of the elderly with dementia. However, it is difficult to generalize because the number of participants is small. Therefore I suggest that should increase the number of participants and study it repeatedly.
\end{abstract}

Keywords: Dementia, Dementia attitude, Self-efficacy for nursing elderly, Educational program for cognitive rehabilitation

\section{Introduction}

\subsection{The need for research}

The proportion of the population aged 65 or older in Korea is increasing annually since 2013 when the value was $12.2 \%$ and is expected to be more than $20 \%$ in 2026, making Korean society to reach a super-aged society [1]. Dementia is a geriatric disease that causes the greatest social and economic costs in this aging society. Dementia, a brain disease, is a complex clinical syndrome that causes continuous damage to the entire brain function including problems related to language, comprehension, judgment, and behavior as well as memory, and widely affects the personality, thinking, and judgment [2]. With family nuclearization and the increased participation of women in economic activities, the situation and responsibilities for supporting the elderly in the home are gradually weakening, and the voice calling for the responsibility of the government and society for elderly support is increasing. Nursing care for the elderly with dementia, therefore, has become a problem that

Article history:

Received (March 26, 2019), Review Result (April 27, 2019), Accepted (May 28, 2019) 
is not affordable at home, and responsibility for caring for elderly people with dementia is shifting from home to community or facility [3].

As the importance of prevention and management of dementia at the national level has been emphasized, a dementia center of each local government and a regional dementia support center have been established to build a systematic and comprehensive dementia management system [4]. These centers, which consist of experts, are responsible for the prevention of dementia and the burden of dementia families through early prevention and early screening, and early intervention for dementia patients [5].

In addition, facilities for community-living elderly and patients with dementia and a service delivery system within the community are established and health professionals are trained and released. In addition, many facilities and communities are seeking to provide quality services by securing scarce manpower by utilizing volunteers is increasing [6].

Dementia knowledge and a positive attitude toward dementia, therefore, are important for effective dementia management for health professionals and volunteers who provide care for the elderly and patients with dementia. The study of education to enable them to take care of the elderly with dementia more efficiently, however, was very limited. The purpose of this study was to evaluate the effects of educational programs for cognitive rehabilitation provided to health professionals and volunteers on their dementia attitude and self-efficacy in the nursing elderly.

\subsection{Purpose of the research}

The purpose of this study is a one-group pretest-posttest study to evaluate the effects of cognitive rehabilitation program education on dementia and the effects of geriatric nursing self-efficacy on participants

\subsection{The hypothesis of the research}

Hypothesis 1. Volunteers who have received cognitive rehabilitation program training will improve their knowledge of dementia attitude

Hypothesis 2. Volunteers who have received cognitive rehabilitation program training will have improved dementia attitude stability scores

Hypothesis 3. Volunteers who have received cognitive rehabilitation program education will improve their total score of dementia attitude

Hypothesis 4. Volunteers who received cognitive rehabilitation program education will improve geriatric nursing self-efficacy

\section{Method}

\subsection{Design and subjects}

The subjects of this non-synchronized study to test the effect of educational programs for cognitive rehabilitation on the participants' dementia attitude and self-efficacy for the nursing elderly were 15 volunteers who registered at a volunteer center in Gyeonggi-do and 11 health professionals working at health education institutions.

\subsection{Measures}

The general characteristics of subjects such as gender, age, education, economic status, and motivation for participating program were directly asked. The dementia attitude referring to 
their knowledge of, sense of, and behavior toward dementia were measured by the Dementia Attitudes Scale (DAS) developed by Carpenter [7] and used in a survey on dementia prevalence [8]. The self-efficacy of the nursing elderly was measured by the Inventory of Geriatric Nursing Self-Efficacy (IGNSE) [9], and geriatric attitude was measured by the Korean version of the Geriatric Attitude Scale: GAS) [10].

\subsection{Data collection}

The educational program for cognitive rehabilitation was provided for five weeks once a week at a volunteer center located in $\mathrm{N}$ city, Gyeonggi-do and a daycare center located in $\mathrm{Y}$ city, Gyeonggi-do from Jul. 20, 2018, to Jan. 30, 2019, the program time per session was seven hours. Data were collected before and after the intervention program, respectively.

Table1. General characteristics of subjects $(\mathrm{N}=26)$

\begin{tabular}{|c|c|c|}
\hline Session & Theory & Practice \\
\hline \multirow{8}{*}{1} & Dementia prevention game overview for everyone & $\begin{array}{l}\text { Game introduction and the whole } \\
\text { learning }\end{array}$ \\
\hline & Elements of brain activation and prevention of dementia (1) & Health gymnastics \\
\hline & \multirow{6}{*}{ Elements of brain activation and prevention of dementia (2) } & Count Arabic numerals \\
\hline & & Singing $1,2,3$ \\
\hline & & Fistball Gymnastics \\
\hline & & Snail \\
\hline & & Thick and Thick (theory) \\
\hline & & Rock Paper Scissors game \\
\hline \multirow{3}{*}{2} & Types of dementia and treatment & Rhythm 2, 3, 4 \\
\hline & Dementia care and gentleness (1) & Bean Pocket Twirl 1 \\
\hline & Preventing dementia in daily life & Mudfish \\
\hline \multirow{5}{*}{3} & Dementia care and gentleness (2) & Collecting words \\
\hline & Why do dementia prevention games work? & Bingo, Advertising puzzle \\
\hline & \multirow{3}{*}{ The qualities and notes of the leader } & Ribbon game \\
\hline & & Sheet Ball game \\
\hline & & Balloon Soccer (Theory) \\
\hline \multirow[t]{2}{*}{4} & $\begin{array}{l}\text { Dementia Elderly and Elderly Long-term Care Insurance } \\
\text { System }\end{array}$ & \multirow{5}{*}{-} \\
\hline & MMSE-DS Theory and practice & \\
\hline \multirow{3}{*}{5} & Field practice & \\
\hline & Test & \\
\hline & Closing Ceremony & \\
\hline
\end{tabular}

\subsection{Educational program for cognitive rehabilitation}

The purpose of the educational program for cognitive rehabilitation used in this study is to allow volunteers to provide effective care for the elderly and demented elderly by providing them with the dementia knowledge and coping methods necessary for the prevention of dementia and dementia care for the elderly and patients with dementia.

In this study, the educational program for cognitive rehabilitation sessions was provided five times, seven hours per session, once a week for five weeks. The theoretical contents 
included the types of dementia and coping, dementia care and gentleness, dementia elderly and elderly long-term care insurance system, cognitive function evaluation, and leader's qualities. The contents for the prevention of dementia included factors for improving brain activation and games for the prevention of dementia. In addition, the opportunity to experience the elderly with dementia was provided through on-the-job training [Table 1].

\subsection{Data analysis}

The collected data were analyzed using SPSS / WIN 18.0 program. The general characteristics and variables related to education were analyzed using descriptive statistics (real number, percentage, mean and standard deviation). Data were collected twice, or before and after the education program. SPSS/WIN 18.0 was used to analyze the data. To be specific, the subjects' demographic information was analyzed with descriptive statistics involving frequency, percentage, mean, and standard deviation. The differences in pretestposttest effects of the education program on subjects' dementia attitudes score and geriatric nursing self-efficacy were analyzed with a paired t-test.

\section{Result}

\subsection{General characteristics}

Table 2. General characteristics of subjects $(\mathrm{N}=26)$

\begin{tabular}{|c|c|c|}
\hline Characteristics & Division & $\mathrm{N}(\%)$ \\
\hline \multirow{4}{*}{ Age } & 40-49 years old & $5(19.2)$ \\
\hline & $50-59$ years old & $8(30.8)$ \\
\hline & Over 60 years old & $12(46.2)$ \\
\hline & other & $1(3.8)$ \\
\hline \multirow{5}{*}{ Education } & Middle school or under & $2(7.7)$ \\
\hline & High school & $6(23.1)$ \\
\hline & College & $2(7.7)$ \\
\hline & University & $15(57.7)$ \\
\hline & other & $1(3.8)$ \\
\hline \multirow{3}{*}{$\begin{array}{l}\text { Experience in Dementia } \\
\text { care }\end{array}$} & present & $8(30.8)$ \\
\hline & absent & $14(53.8)$ \\
\hline & other & $4(15.4)$ \\
\hline \multirow{6}{*}{ Motivation participation } & Acquisition of certification & $6(23.1)$ \\
\hline & To have a job & $4(15.4)$ \\
\hline & Economic assist & $1(3.8)$ \\
\hline & Leisure activity & $1(3.8)$ \\
\hline & Recommendation & $2(7.7)$ \\
\hline & Others & $8(30.8)$ \\
\hline
\end{tabular}




\subsection{Effects on dementia attitude and self-efficacy for nursing elderly}

Table 3. Effects on dementia attitude and self-efficacy for nursing elderly ( $N=26)$

\begin{tabular}{|c|c|c|c|c|c|}
\hline Parameter & Division & Pre-test $(\mathrm{M} \pm \mathrm{SD})$ & Post-test $(\mathrm{M} \pm \mathrm{SD})$ & $\mathrm{t}$ & $\mathrm{p}$ \\
\hline \multirow{3}{*}{ DAS } & Knowledge & $55.35 \pm 10.19$ & $56.62 \pm 7.66$ & -.692 & .495 \\
\cline { 2 - 6 } & Stabilization & $36.35 \pm 7.85$ & $37.23 \pm 8.47$ & -.418 & .679 \\
\cline { 2 - 6 } & Total score & $91.69 \pm 15.64$ & $93.85 \pm 13.40$ & -.630 & .534 \\
\hline IGNSE & & $45.46 \pm 8.16$ & $46.15 \pm 8.25$ & -.437 & .666 \\
\hline
\end{tabular}

\section{Discussion}

The purpose of this study was to investigate the effects of cognitive rehabilitation program education on volunteers' attitudes toward dementia and nursing self-efficacy in elderly volunteers.

In this study, the posttraumatic attitude knowledge score, dementia attitude stability score, and dementia attitude score did not show statistically significant but it was improved mean score. The results of this study are as follows. First, it is difficult to directly compare the dementia attitude toward volunteers. However, the effect of simulation education on the cognitive impairment of elderly people is more improved than that of lecture education through theoretical education, clinical practice, and simulation [11]. Therefore, we think that the dementia theory, the games for improvement of dementia cognition, and the field practice have been effective teaching methods for dementia attitude.

The knowledge of dementia was similar to that of the present study, although the knowledge of dementia knowledge after three dementia education programs was not statistically significant in posttraumatic care hospitals [12][13]. Therefore, it is suggested that the development of a program to improve the knowledge of dementia at the time of education is necessary. The elderly nursing self-efficacy score was not statistically significant but showed an improvement in the mean score. The results of this study are as follows. First, the self-efficacy of nursing students was not statistically significant. These results support the report that higher clinical career experience, higher position, and higher self-efficacy [14].

The development of a dementia education program in this study is a combined program including cognitive rehabilitation and dementia knowledge. Therefore, it was not only theoretical knowledge about dementia but also a practical application program.

\section{Conclusion}

This study analyzed the effects of cognitive rehabilitation program education on dementia attitude and self-efficacy on dementia among volunteer centers and members of the Korea Senior Care Research Association.

The results of the analysis showed that there was no statistically significant difference between subjects' dementia attitude knowledge, dementia attitude stability, dementia total attitude, and elderly nursing self-efficacy. However, the average score showed improvement. Therefore, it is necessary to continuously supplement and apply the program of this study which improved the dementia attitude and the elderly nursing self-efficacy which is an important factor in the care of the elderly with dementia. 


\section{References}

[1] Statistics, "Elderly Statistics," Seoul, Korea, (2012)

[2] J. Cerejeira, L. Lagarto and E. B. Muka etova-Ladinska, "Behavioral and psychological symptoms of dementia," Front Neurol, vol.3, no.73, (2012) DOI: 10.3389/fneur.2012.00073

[3] B. Cheong, Korean Association for Survey Research, vol.27, no.2, pp.503-518, (2007)

[4] S. H. Ryu, "The role of the local center for dementia in the management system of dementia in Seoul," J Korean Geriatr psychiatry, vol.11, no.1, pp.12-15, (2007)

[5] D. Y. Lee, "Seoul dementia management project and Seoul metropolitan center for dementia," J Korean Geriatr psychiatry, vol.11, no.1, pp.8-11, (2007)

[6] S. Y. Jung and H. U. Baik, Mental health \& Social Work, vol.21, no.12, pp.60-89, (2005)

[7] B. R. Yoon, Y. S. Shim, Y. D. Lee, K. O. Na, S J. Hong and D. W. Yang, Dement Neurocogn Disord, vol.11, pp.13-17, (2012)

[8] Ministry of Health and Welfare, 2012 Nationwide Study on the Prevalence of Dementia in Korean Elders, (2013)

[9] J. E. Jang, "The effects of emotion-focused individual intervention for family caregivers of people with early stages of dementia," Seoul National University, Seoul, (2016)

[10] Y. S Park, Y. J. Jee, S. H. Bae, "Effects of a dementia family support program on families' attitude towards dementia, desire for institutionalization, caregiving behavior and caregiving burden," Asia-pacific Journal of Multimedia Services Convergent with Art, Humanities, and Sociology, vol.7, no.8, pp.781-793, (2017)

[11] V. Kontis, J. E. Bennett, C. D Mathers, G, Li, K. Foreman, and M. Ezzati, "Future life expectancy in 35 industrialized countries: projections with a Bayesian model ensemble," Lancet, pp.1323-1335, (2017)

[12] E. H. Kong, "The effects of a dementia education program on certified geriatric caregivers in a nursing home," J Korean Acad Psychiatr Ment Health Nurs, vol.19, no.4, pp.349-358, (2010)

[13] J. Y. Kim, N. R. Heo, H. J. Jeon, and D. Y. Jung, "Effects of simulation education on the communication competence, academic self-efficacy, and attitude about the elderly for nursing students: A learning approach based on an elderly-with-cognition-disorder scenario," J Korean Acad Soc Nurs Educ, vol.21, no.1, pp.54-64, (2015)

[14] A. L Han and S. H. Kwon, "Effects of self-leadership and self-efficacy on the nursing performance of nurses working in long-term care hospitals,” J. Korean Gerontol Nurs, vol.18, no.1, pp.12-21, (2016) 